\title{
O FALIBILISMO EPISTEMOLÓGICO DE KARL POPPER
}

\author{
THE EPISTEMOLOGICAL FALLIBILISM OF KARL POPPER
}

\author{
FERNANDO RUIZ ROSARIO ${ }^{1}$ \\ Universidade Federal de Minas Gerais (UFMG)/ Instituto Federal de Educação, \\ Ciência e Tecnologia de Minas Gerais (IFMG/ Campus Ibirité) - Brasil \\ fruizrosario@gmail.com
}

\begin{abstract}
RESUMO: O falsificacionismo popperiano, ao propor que teorias científicas devem ser tomadas enquanto conjecturas, implica uma visão falibilista sobre o conhecimento. Ao assumir que não existe fonte segura para fundamentar o conhecimento, Popper precisa repensar o que seja o conhecimento, já que não existiriam razões suficientes para que determinássemos que uma teoria é certa. Para tanto, utiliza-se de uma concepção não justificacionista, fazendo da crítica o critério de racionalidade. O resultado desse projeto popperiano leva a uma concepção falibilista sobre o conhecimento: não temos certeza se aquilo que sabemos é certo, mas ainda podemos dizer que sabemos algo.
\end{abstract}

PALAVRAS-CHAVE: Falibilismo. Falsificacionismo. Justificação. Epistemologia.

ABSTRACT: Popperian falsificationism, in proposing that scientific theories should be taken as conjectures, implies a fallibilist view of knowledge. By assuming that there is no secure source for knowledge, Popper must rethink what is knowledge, since there would be no sufficient reason for us to decide that a particular theory is right. To do so, he uses a non-justificationist conception, making criticism the criterion of rationality. The result of this Popperian project leads to a fallibilist conception of knowledge: we are not sure if what we know is right, but we can still say that we know something.

KEYWORDS: Fallibilism. Falsificationism. Justification. Epistemology.

\section{A ORIGEM DO FALIBILISMO POPPERIANO}

O falibilismo epistemológico é uma consequência da teoria falsificacionista da ciência defendida por Karl Popper, que por sua vez requer uma posição não justificacionista. Segundo essa teoria, a ciência é formada por sistemas de teorias articuladas que explicam o mundo e lançam predições com base em condições dadas. Como existem diversas teorias internamente coerentes, são aceitas como científicas apenas aquelas que satisfazem um critério de demarcação.

O critério de demarcação proposto por Popper é a falseabilidade, que é uma característica de teorias que são passíveis de serem submetidas a testes

\footnotetext{
1 Doutorando em Filosofia pela Universidade Federal de Minas Gerais (UFMG) e professor do Instituto Federal de Educação, Ciência e Tecnologia de Minas Gerais (IFMG/ Campus Ibirité).
} 
empíricos. Testes bem-sucedidos resultam em corroboração, já testes que falham levam à refutação de teorias. Uma teoria deve, portanto, dizer algo sobre o mundo, afirmando ou negando certa configuração possível desse mundo, de maneira que, caso o observado não seja tal como o descrito, ela deva ser considerada falsa. Assim, por exemplo, se uma teoria $T$ afirma que um evento $x$ ocorrerá em determinadas condições, caso satisfeitas as condições e não se verificar a ocorrência de $x$, então $T$ será falsa; caso, porém, $x$ ocorra, T possuirá corroboração empírica. Teorias que foram falsificadas serão descartadas ${ }^{2}$, enquanto aquelas que foram bem corroboradas serão utilizadas pela ciência.

Acontece que, ao contrário do que pensa uma visão epistemológica ingênua presente no senso comum, a corroboração de $T$ não garante que ela seja verdadeira. Mesmo que diversas predições de $T$ sejam verificadas em repetidos testes, realizados de maneira independente por diferentes cientistas, $T$ pode ser falsa. E, segundo a constatação de Popper, é impossível proceder qualquer teste que seja capaz de verificar que uma teoria é verdadeira de maneira conclusiva. Embora a busca pela verdade seja o escopo da ciência, os procedimentos empíricos dos quais dispomos no máximo revelam que uma determinada teoria é "boa", no sentido de que explica adequadamente o mundo, de que permite fazer predições com algum grau de confiabilidade e de que se apresenta como uma melhor explicação do que outras disponíveis.

Isso impõe para a ciência e para o conhecimento em geral que a certeza de que algo seja verdadeiro não é possível. A noção de verdade, que em Popper será tratada como correspondência, muitas vezes é utilizada como sinônimo de certeza, pois quando tenho certeza de algo, acredito que isso seja verdadeiro. Porém, se $x$ é o caso, $x$ é verdadeiro, e se possuo razões para acreditar em $x$, digo que é certo e, nestes casos, certeza é um sentimento de segurança sobre algo e diz respeito ao sujeito, enquanto a verdade diz respeito à proposição e sua relação com o mundo. Pode ser que, mesmo que eu tenha razões para crer em $x, x$ não seja o caso e seja falso, da mesma maneira que $x$ pode ser verdadeiro mas não existam razões para a certeza de $x$. Tal conclusão se contrapõe ao ideal moderno de conhecimento indubitável, abrindo a perspectiva de uma visão falibilista do conhecimento. Longe, porém, de cair em um ceticismo, a análise popperiana admite que, mesmo incerta, a ciência ainda assim é conhecimento.

No presente artigo, será discutido como o falsificacionismo desemboca em uma perspectiva não justificacionista. Cabe ressaltar que algumas questões que envolvem o falsificacionionismo, tais como os problemas que envolvem testes e procedimentos metodológicos de seleção (aceitação ou refutação) de teorias, não serão aqui problematizados. O foco do presente trabalho é analisar alguns dos

2 O processo de seleção de teorias, que passa pela refutação ou aceitação, requer alguns procedimentos metodológicos para não se cair em um dogmatismo. Conforme aponta Lakatos, existe um tipo de falsificacionismo dogmático que considera a refutação de uma teoria de maneira definitiva, baseada na aceitação incondicional de enunciados básicos (1979, p. 115), o que seria um problema para Popper dada sua pressuposição falibilista do conhecimento. Porém, Popper nunca defendeu um falsificacionismo dogmático, mas sim um falsificacionismo metodológico (LAKATOS, 1979, p. 224), pois aceitava enunciados básicos como numa espécie de convenção (POPPER, 2007, p. 113). 
fundamentos epistemológicos que estão na base da obra de Popper que são cruciais para compreender seu falsificacionismo. A partir dessa perspectiva, aqui centraremos esforços para compreender como o racionalismo popperiano impacta em sua visão epistemológica, levando a uma concepção falibilista sobre o conhecimento.

\section{O PROBLEMA DE JUSTIFICAÇÃO DE CRENÇAS}

A filosofia de Karl Popper possui um núcleo central de teses que articulam de maneira sistemática todas as suas obras. Esse núcleo pretende fornecer:

[...] uma concepção racionalista da ciência, incluindo uma estratégia ou metodologia para operacionalizá-la, como um meio termo entre a concepção dogmática, tanto fundacionista quanto convencionalista, e a concepção cética, em suas versões relativista ou instrumentalista. (CHIAPPIN, 2010, p. 168).

Uma questão para a concretização desse projeto diz respeito à justificação de crenças. Para Popper (1987, p. 52), perguntar-se sobre a justificação está relacionado com a avaliação de teorias e crenças que competem entre si. Essa competição se dá quando duas ou mais teorias possuem diferentes explicações inconsistentes para o mesmo fenômeno e, portanto, não é possível aceitar ambas como verdadeiras sem cair em contradição. A relação entre justificação e avaliação de teorias acontece porque, ao avaliar teorias ou crenças busca-se encontrar aquela que seja verdadeira. Uma crença ou teoria justificada seria aquela que possibilita uma escolha racional que levaria à certeza.

Porém, Popper rejeita a possibilidade de justificação positiva, afirmando que não podemos dar nenhuma razão positiva para considerar nossas teorias como verdadeiras (POPPER, 1987, p. 52). Significa dizer que, ao avaliarmos diferentes teorias, não somos capazes de fornecer razões suficientes que possibilitem levar à certeza de que uma seja a verdadeira. Tal problema aparece já na primeira seção da Lógica da Pesquisa Científica, quando Popper apresenta o problema geral da indução, dizendo que "está longe de ser óbvio, de um ponto de vista lógico, haver justificativa no inferir enunciados universais de enunciados singulares, independentemente de quão numerosos sejam estes" (POPPER, 2007, p. 27-28). E tal problema se aplica as ciências empíricas, uma vez que "As ciências empíricas são sistemas de teorias" e "As teorias científicas são enunciados universais" (POPPER, 2007, p. 61).

O problema da justificação, no entanto, é mais antigo. Na modernidade, por exemplo, na primeira das Meditações, Descartes afirma que recebeu falsas opiniões como verdadeiras, não podendo ser confiável aquilo que estivesse fundamentado em princípios não sólidos, de tal maneira que seria necessário examinar os alicerces fundantes do conhecimento (DESCARTES, 1979, p. 86). Para justificar o conhecimento, Descartes procurará encontrar um princípio racional que possibilite 
decidir sobre a aceitação ou recusa de uma determinada crença, e que possibilite erigir um conhecimento sobre uma base justificada.

Justificar, que aqui aparece como a busca de certeza, leva à uma noção de conhecimento enquanto conhecimento certo. Nas primeiras Regras para a direção do espírito, Descartes aponta que a finalidade dos estudos científicos deve ser a emissão de juízos sólidos e verdadeiros, certos e indubitáveis, e que isso só é possível quando a verdade do conhecimento é conhecida por uma intuição clara e evidente, ou quando podem ser deduzidos de uma intuição desse tipo (DESCARTES, 1996, p. 61-72). Descartes diz que a intuição é exigida para qualquer raciocínio, como, por exemplo, quando se diz que 2 mais 2 é igual a 3 mais 1 , de maneira que não apenas intuitivamente se sabe que o resultado de 2 mais 2 é igual a 4 e, igualmente, 3 mais 1 também é igual a 4, são 4, como, além disso, se chega a conclusão que destas duas proposições se chega aquela terceira. Para Descartes, portanto, o método é o meio pelo qual se alcança o conhecimento, uma vez que proporcionaria nunca tomar o falso por verdadeiro uma vez que as regras sejam seguidas, permitindo conhecer tudo o que existe para ser conhecido.

Porém, a intuição é imprescindível para que o processo do conhecimento possa ser realizado. A partir da intuição seria possível formular uma base do conhecimento composta por um núcleo de enunciados simples, dos quais os mais complexos poderiam ser deduzidos, cuja justificação se daria pela evidência: "só existem poucas naturezas puras e simples que podemos intuir imediatamente e por si mesmas, independentemente de qualquer outra, e na mesma experiência, e por alguma luz inata em nós.” (DESCARTES, 1996, p. 91, tradução minha).

Conforme aponta Chiappin, assumir uma base última, indiscutível e irrevogável possibilita avaliar quaisquer outros enunciados, rejeitando aquilo que não pode ser deduzido ou justificado dessa base. E, adotando um modelo geométrico como paradigma metodológico, bem como os fundamentos da lógica, extrai-se teoremas dentro do sistema de conhecimento, possibilitando identificar enunciados verdadeiros e enunciados falsos. Mas tal procedimento é caracterizado como dogmático, pois "partilha da crença de um fundamento último para o conhecimento", formado por uma "base última, indiscutível e irrevogável" (CHIAPPIN, 2010, p. 156-157).

A fundamentação do conhecimento em um núcleo base de certezas cuja verdade é extraída de sua evidência colapsa com a crítica de Hume. Ele divide os objetos da razão humana em dois tipos: em relações de ideias e em questões de fato (HUME, 2004, p. 53). Do primeiro tipo são todas as afirmações que sejam intuitivas ou demonstrativamente certas, de maneira tal que seus valores de verdade independam da existência dos objetos de que tratam, ou seja, podem ser estabelecidas a priori. Os exemplos dados por Hume são a geometria, a álgebra e a aritmética.

A segunda espécie, as questões de fato, não podem ser estabelecidas a priori. Diz Hume: "O contrário de toda questão de fato permanece sendo possível, porque não pode jamais implicar contradição, e a mente o concebe com a mesma facilidade e clareza, como algo perfeitamente ajustável à realidade" (HUME, 2004, 
p. 54). O critério de distinção entre os dois tipos de objetos da mente é um critério lógico: pensar o contrário das relações de ideias implica contradição, já o contrário de questões de fato é perfeitamente possível.

O ponto defendido por Hume é que o conhecimento de questões de fato depende de uma relação de causa e efeito, e que tal relação não pode ser estabelecida seguindo-se critérios da lógica, dependendo inteiramente da experiência. Toda explicação de fato recorre à outra explicação de fato para ser explicitada. Por exemplo, se um homem encontra um relógio em uma ilha deserta concluirá que algum outro homem esteve anteriormente na ilha, supondo-se que existe uma correlação entre o fato atual, encontrar um relógio, e o fato passado, que alguém esteve na ilha. A sua relação, neste contexto, acontece em uma inferência causal, na tentativa de estabelecer um conhecimento que vá além do dado pelos sentidos e pela memória. Esse conhecimento, por sua vez, passa pela criação de uma conexão causal, cuja relação jamais pode ser estabelecida a priori:

Nenhum objeto jamais revela, pelas qualidades que aparecem aos sentidos, nem as causas que o produziram, nem os efeitos que dele provirão; e tão pouco nossa razão é capaz de extrair, sem auxílio da experiência, qualquer conclusão referente à existência efetiva de coisas ou questões de fato. (HUME, 2004, p. 56).

Hume diz que facilmente se aceitaria que a relação causal não é descoberta pela razão, mas pela experiência quando nos referimos a assuntos que sabemos ter desconhecido no passado, mas que surge uma dificuldade quando se tratam de questões de fato que estamos familiarizados desde que viemos ao mundo "que apresentam uma íntima analogia com o curso geral da natureza, e que supomos dependerem das qualidades simples de objetos sem nenhuma estrutura secreta de partes" (HUME, 2004, p. 57).

Diz, também, que julgaríamos sermos capazes de inferir que uma bola de bilhar comunicaria seu movimento à outra por meio do impulso, caso jamais tivéssemos tido essa experiência antes; mas, se nos fosse apresentado o caso, perguntando o que aconteceria com a segunda bola, sem que tivéssemos tido qualquer experiência, apenas poderíamos dar uma resposta arbitrária e com uso da imaginação, uma vez que não há nada na primeira bola que permita predizer o movimento da segunda, cujos movimentos são totalmente distintos. E assim, conclui: "todo efeito é um acontecimento distinto de sua causa" (HUME, 2004, p. 59).

Para Hume, somos levados a inferir o efeito pela causa, ou a causa pelo efeito, apenas pelo hábito. Através de uma série de relações, como de conjunção constante ou sucessão regular, o entendimento realiza um salto do conhecimento dado para o desconhecido, realizando uma predição. O procedimento vai do observado, aquelas experiências passadas de causalidade, para o não observado, prevendo que no futuro tal relação causal voltará a se repetir. Isso porque a ideia de conexão necessária entre causa e efeito não é fruto da razão, uma vez que não existe nenhum argumento demonstrativo que permita, sem a experiência, 
estabelecê-los. Assim, não existe nenhuma prova, pela razão, de que as experiências de casos particulares no passado se darão da mesma maneira no futuro. Se o princípio fosse racional, poderíamos estabelecer a uniformidade da natureza:

Se fosse a razão [que determinasse a inferência causal], ela o faria com base no princípio de que os casos de que não tivemos experiência devem se assemelhar aos casos de que tivemos experiência, e de que o curso da natureza continua sempre uniformemente o mesmo. (HUME, 2009, p. 117-118, destaque no original).

O problema apontado por Hume, o qual Popper chamará de problema geral da indução, está na impossibilidade de se estabelecer uma justificação para indução por meio da experiência ou de demonstração dedutiva. Para se estabelecer um Princípio de Uniformidade da Natureza (PU), ou afirmaríamos que as relações causais da natureza serão, no futuro, tal como observamos no passado, com base na nossa experiência, ou necessitaríamos de um elemento que permitisse a extração dessa conclusão do PU sem cair em circularidade. A primeira opção, conforme já explicitado, não funciona, uma vez que, mesmo que a natureza tenha sido uniforme até aqui, não implica contradição pensar que ela mude. E, no segundo caso, não é possível pressupor que o futuro será semelhante ao passado, sem já ter em mãos o princípio de uniformidade da natureza. Ainda assim, possuímos crença em regras gerais. Hume não defende a inferência causal como sendo fundamentada na razão, embora faça referências a ela como um raciocínio de natureza mais confiável que outros mecanismos formadores de crenças. Fato que não muda a natureza da inferência causal, sendo ela considerada um mecanismo psicológico da mente humana.

Aponta Chiappin que a solução empirista para a ampliação do conhecimento é propor uma base última da ciência, formada por proposições particulares empíricas, que possibilitam a formação de proposições sintéticas universais que descrevem regularidades. Diferente do racionalismo de Descartes, que justifica sua base em termos de evidência intelectual, o empirismo humeano propõe uma solução prática que, ao mesmo tempo, contorna o problema da indução e possibilita justificar o conhecimento por meio de aspectos epistêmicos e psicológicos (CHIAPPIN, 2010, p. 153).

Como inferências causais geram vivacidade estável na mente, ela acaba atuando com uma força tal que pode justificar sua utilização, mesmo que desprovida de fundamentação lógica, baseando-se no hábito. Apesar de Hume reconhecer que não existe justificação lógica para o problema da indução, encontra no hábito a explicação psicológica para o problema. O problema, aponta Popper, é que tal solução desemboca numa espécie de ceticismo epistemológico, uma vez que uma parcela considerável de nossas crenças é baseada em uma espécie de "fé irracional' (POPPER, 1999, p. 16).

A indução continua a ser um problema central de uma teoria do conhecimento, dada a impossibilidade de se estabelecer, com base na lógica da 
época, uma sustentação que fosse semelhante àquela dada pelas inferências dedutivas. A dedução se apresenta como um método seguro de extração de verdade, uma vez que a assunção de proposições universais garante que a relação entre as premissas permita extrair validamente a conclusão com base nas informações já disponíveis. A indução, por outro lado, pretende ir para além do conteúdo assumido nas premissas, efetuando uma espécie de generalização para todos os casos, mas cuja sustentação não está disponível nos casos já observados.

\title{
3 O NÃO JUSIIFICACIONISMO
}

Para Popper o problema da justificação é irrelevante e todas as soluções para respondê-los são incorretos, uma vez que a questão principal está em estabelecer um critério de demarcação (CHIAPPIN, 2010, p. 174). A solução que ele apresenta se baseia na assimetria encontrada na tentativa de justificação de enunciados universais, cuja confirmação seria impossível empiricamente, restando apenas a possibilidade de rejeitá-los pela falsificação:

\begin{abstract}
Minha posição está alicerçada numa assimetria entre verificabilidade e falseabilidade, assimetria que decorre da forma lógica dos enunciados universais. Estes enunciados nunca são deriváveis de enunciados singulares, mas podem ser contraditados pelos enunciados singulares. Consequentemente, é possível, através de recurso a inferência puramente dedutivas, (com auxílio do modus tollens, da lógica tradicional), concluir acerca da falsidade de enunciados universais a partir da verdade de enunciados singulares. Essa conclusão acerca da falsidade de enunciados universais é a única espécie de inferência estritamente dedutiva que atua, por assim dizer, em "direção indutiva", ou seja, de enunciados singulares para enunciados universais. (POPPER, 2007, p. 43).
\end{abstract}

A partir do desenvolvimento de suas regras metodológicas, Popper acredita ser possível responder à questão da possibilidade de avaliar teorias ou crenças, mas nega o pressuposto de que seja possível apresentar justificação positiva para teorias. Assim, ele diz que "não podemos dar nenhuma justificação positiva, nem nenhuma razão positiva, das nossas teorias e das nossas crenças", o que significa dizer que não podemos fornecer razões positivas que justifiquem a verdade de nossas teorias (POPPER, 1987, p. 52).

Acusado de se aproximar do ceticismo ao dizer que não é possível justificar teorias e crenças, Popper (1987, p. 53) afasta tal possibilidade ao dizer que podemos escolher entre teorias concorrentes, em termos de aproximação a verdade, oferecendo razões críticas que possibilitem a escolha entre diversas teorias ou crenças.

A diferença entre as razões críticas e as razões positivas é que as primeiras não pretendem dar razões suficientes para escolha tal como as segundas. Elas fornecem elementos conjecturais que possibilitam a escolha, não definitiva, que pode ser abandonada se surgirem novas razões. A ideia de que conhecimento é 
uma crença justificada é substituída pela ideia de crença conjectural, evitando problemas oriundos do justificacionismo, como o ceticismo e o irracionalismo.

Não foram só os racionalistas, os empiristas e os kantianos que partilharam tal suposto [o justificacionismo], mas também os cépticos e os irracionalistas. Os cépticos, obrigados a admitir que não podemos justificar as nossas teorias ou crenças, declaram a ruína da busca do conhecimento, ao passo que os irracionalistas (os fideístas, por exemplo), devido à mesma admissão fundamental, declaram a ruína da busca de razões - isto é, de argumentos racionalmente válidos — de tentar justificar o nosso conhecimento, ou, antes, as nossas crenças, apelando para a autoridade, como a autoridade de fontes irracionais. Ambos supõem que a questão da justificação ou da existência de razões positivas é fundamental: ambos são justificacionistas clássicos. (POPPER, 1987, p. 54).

Ao abandonar a posição justificacionista, Popper propõe que o problema da teoria do conhecimento está em outra direção: o de estabelecer um critério de demarcação. A questão é deslocada, então, do problema de tentar justificar conhecimento, para o de delinear aquele tipo de conhecimento que, mesmo sendo incerto, é preferível. O problema passa a ser o de diferenciar quais proposições são consideradas científicas daquelas que se encontram em domínios extracientíficos. O critério apresentado, o da falseabilidade, é também um critério empírico:

Só reconhecerei um sistema como empírico ou científico se ele for passível de comprovação pela experiência. Essas considerações sugerem que deve ser tomado como critério de demarcação, não a verificabilidade, mas a falseabilidade de um sistema. Em outras palavras, não exigirei que um sistema científico seja suscetível de ser dado como válido, de uma vez por todas, em sentido positivo; exigirei, porém, que sua forma lógica seja tal que se torne possível validá-lo através de recurso a provas empíricas, em sentido negativo: deve ser possível refutar, pela experiência, um sistema científico empírico. (POPPER, 2007, p. 42).

Tal critério, conforme salienta Chiappin (2010, p. 175), está definido em torno da assimetria de enunciados universais que, através de um sistema metodológico utilizando-se o Modus Tollens, permite contradizer enunciados universais através de enunciados singulares: "Com este critério redefine-se a noção de conhecimento científico não mais como conhecimento justificado mas como aquele capaz de submeter-se ao teste crítico da falseabilidade". Esse deslocamento do problema da justificação para a demarcação pretende evitar posições dogmáticas, ao não precisar dispor de uma base inquestionável de proposições bases. Porém, ainda é insuficiente para responder ao cético, uma vez que o critério de demarcação, apesar de evitar a metafísica, ainda não é capaz de oferecer razões suficientes para suplantar um argumento de autoridade ou o convencionalismo. 
Para tentar suplantar esse obstáculo, ao lado da construção de uma visão racionalista da ciência, Popper irá estabelecer uma concepção de ciência dinâmica, progressiva e racional, que possibilite a revisão de seus sistemas teóricos, sem evitar o progresso do conhecimento. Assim, o critério de demarcação aparece como uma convenção ${ }^{3}$ :

Meu critério de demarcação deve, portanto, ser encarado como proposta para que se consiga um acordo ou se estabeleça uma convenção. As opiniões podem variar quanto à oportunidade de uma convenção do gênero. Todavia, uma discussão razoável dos temas em pauta só é viável se os interlocutores têm um objetivo comum. A determinação desse objetivo é, em última análise, uma questão de tomada de decisão, ultrapassando, por conseguinte, a discussão racional. (POPPER, 2007, p. 3839).

Complementa, em nota, que uma discussão racional pressupõe interlocutores interessados na verdade e que se disponham a considerar as diversas manifestações possíveis sobre o tema. As dificuldades aqui encontradas não são poucas. Primeiro, porque a possibilidade de convencionar objetivos para a ciência requer a negação da perspectiva racionalista clássica, que a pressupõe como uma atividade detentora de conhecimento incontestável. Segundo, porque embora o debate crítico seja a única ferramenta disponível que seja capaz de superar o dogmatismo, dada a impossibilidade de se assentar a ciência em bases lógicas ou apriorísticas, ainda não é certo que seja capaz de contemplar as diversas vozes dissonantes no debate. Porém, será essencial para a configuração do conhecimento em termos falibilistas.

\section{AS IMPLICAÇÕES DO NÃO JUSTIFICACIONISMO}

Popper, de partida, assume certos compromissos. É racionalista, acreditando na razão como a melhor maneira de se construir conhecimento. Aquilo que conhecemos, por sua vez, remete a um mundo externo, independente da criação humana, implicando o realismo. Embora criemos teorias que tentem explicar o mundo, é observando o mundo que teremos que decidir qual teoria melhor o explica. A criação de uma teoria, afirma Popper (1972, p. 78), não é uma derivação da natureza, mas uma tentativa do intelecto em compreendê-la. Porém, tal tentativa não depende de justificação, desde que a teoria tenha passado pela crítica. Assim, o filósofo mostra que a discussão acerca do conhecimento deve ser deslocada da

\footnotetext{
${ }^{3}$ Esse convencionalismo popperiano, que configura seu falsificacionismo metodológico, enfrentará outro tipo de dificuldade, que será chamado de problema Duhem-Quine, já que o Modus Tollens permite dizer que, se uma teoria $T$ implica $p$, e $p$ não se seguir, então é o caso de não- $T$. Porém, $T$ nunca é apenas uma teoria isolada, e pressupõe uma série de hipóteses auxiliares, ou seja, $T$ é um sistema de teorias e condições iniciais. Oras, não é possível, a partir do Modus Tollens, dizer se uma ou várias teorias são falsas, ou se as hipóteses auxiliares. Para uma discussão mais detalhada, ver Zahar (1997).
} 
questão sobre os fundamentos para a questão sobre a análise de testes e consequência de teorias.

O programa racionalista clássico faz uma associação intrínseca entre a justificação do conhecimento em uma base fundante como requisito para a racionalidade seja ela uma intelecção, um juízo sintético a priori ou uma percepção. Para Popper, a racionalidade encontra-se do outro lado do túnel: não devemos olhar de onde vêm nossas teorias, mas sim, para sua crítica e possibilidade de revisão, de modo que a questão que deve ser colocada pela Epistemologia é "como submeter a testes enunciados científicos, considerando suas consequências dedutivas?", passando de uma abordagem psicologística para uma abordagem objetiva do conhecimento (POPPER, 2007, p. 105). De maneira que a questão não seja mais as fontes do conhecimento, mas como identificar e eliminar erros:

\begin{abstract}
A primeira ideia, falsa, a de que precisamos justificar nosso conhecimento, ou nossas teorias, por meio de razões positivas - isto é, capazes de demonstrá-las, ou pelo menos de mostrar que são altamente prováveis; de qualquer forma, por razões melhores do que a de que resistiram à crítica. Esta ideia implica, penso, que precisamos apelar para uma fonte última ou autoritária de conhecimento verdadeiro; o que deixa em aberto ainda a natureza dessa autoridade que pode ser humana (como a observação ou a razão) ou sobre-humana (e portanto sobrenatural). (POPPER, 1972, p. 57-58, grifo no original).
\end{abstract}

Para Popper, nem a observação e nem a razão são autoridades. Por ser assim, não há nenhuma autoridade humana que possa decretar o que seja verdadeiro, estando, portanto, a decisão sobre a verdade para além da capacidade humana. Todo conhecimento, porém, é humano e, consequentemente, permeado de "erros, preconceitos, sonhos e esperanças", de sorte que resta ao homem procurar a verdade, submetendo todo o âmbito do conhecimento à crítica.

Conforme aponta Bueno (2010, p. 84), o abandono do justificacionismo constitui uma das principais características do programa de Popper, que se reflete em sua solução da indução, associando o racionalismo à crítica. Além disso, a adoção dessa postura se deve ao compromisso de Popper em construir uma posição racionalista que evite o ceticismo e o dogmatismo, dentre outras posições intermediárias, como o relativismo e o instrumentalismo. Segundo Chiappin (2010, p. 149), o projeto de Popper pretende "dar conta da dinâmica e do aumento do conhecimento".

Embora em alguns momentos Popper justifique sua adoção ao racionalismo por meio do irracionalismo, como sendo fruto de uma fé irracional (POPPER, 1999, p. 16), o seu não justificacionismo se revela na maneira de analisar o conhecimento independentemente das razões que nos levam a assumi-lo. Conforme aponta Miller (2012, p. 95), não é possível racionalmente exigirmos razão, mas, uma vez que ela é aceita, ela serve como uma espécie de proibição que exclui instâncias do irracionalismo. 
Provavelmente a mais impactante solução não justificacionista desse programa esteja na solução da indução apresentada pelo filósofo. Para Popper a indução é uma face do problema de demarcação e, uma vez resolvido esse problema, não faz mais sentido falar em indução. E a solução da demarcação recai na assimetria da confirmação de enunciados universais que formam leis: "Só a falsidade de uma teoria pode ser inferida da evidência empírica, inferência que é puramente dedutiva" (POPPER, 1972, p. 84, grifo no original).

Para esclarecer, utilizaremos a analogia entre a ciência e uma construção. Uma construção confiável é aquela firmada sobre um alicerce seguro, devidamente construída sobre bases sólidas. Na ciência, porém, não temos como verificar a solidez dessa base, sendo difícil dizer sobre sua segurança. Porém, se isso acontece com uma construção, saberemos se ela é segura se se mantiver em pé após passar por várias intempéries. O teste, nas ciências, é a submissão à crítica. E, se estamos dispostos a explicar o mundo sob a forma de leis e teorias, "Se essa é nossa tarefa, o procedimento mais racional é o método das tentativas - da conjectura e da refutação. Precisamos propor teorias, ousadamente; tentar refutá-las; aceitá-las tentativamente, se fracassarmos." (POPPER, 1972, p. 81, grifo no original).

Cabe ressaltar que o caráter não justificacionista do conhecimento não significa dizer que não existem justificativas para qualquer assunção de regras metodológicas ou princípios. Tanto que o projeto de Popper assume certas posições metafísicas e epistemológicas e, partir delas formula suas regras metodológicas. Essa assunção de compromissos metafísicos, porém, não pode ser estabelecida empiricamente, e sequer pode ser decidida por falseamento. A análise que Popper desenvolve, conforme já explicitado, se dá pela tentativa de mensurar as consequências das posições assumidas.

Nesse cenário, algumas objeções ao não justificacionismo de Popper parecem se desmanchar. Lam (2007, p. 12-13), ao abordar o pensamento de Bartley, diz que há na filosofia de Popper um "sopro de justificacionismo" quando este tenta defender o racionalismo como uma decisão irracional. Porém, esse fundo irracional não está de fato minando a posição racionalista de Popper, mas antes, evidencia a dificuldade de se decidir empiricamente por uma posição metafísica, restando-nos apenas avaliá-la por suas consequências.

Por exemplo, se um cientista encontra um problema na resolução de uma determinada questão. Pouco importa se tal cientista encontra sua solução depois de horas sentado em seu laboratório pensando em como resolver tal problema, se, ao sair de seu laboratório, ouviu uma conversa entre dois jovens que o inspirou, ou ainda se sonhou com uma solução miraculosa. A origem da "ideia", por assim dizer, não interfere na sua aplicação, desde que ela possa passar pelos testes críticos propostos pela metodologia. De maneira que "A experiência humana, tanto na vida comum como em ciência, adquire-se fundamentalmente através do mesmo procedimento: a invenção livre, injustificada e injustificável de hipóteses, antecipações ou expectativas, e sua subsequente testagem.” (POPPER, 1987, p. 264-265). 


\section{O FALIBILISMO EPISTEMOLÓGICO}

Um dos objetivos da obra de Karl Popper é a defesa do pensamento livre, crítico e progressivo. Ele defende que uma posição cética em relação ao conhecimento não condiz com a produção científica, ao mesmo tempo em que posições dogmáticas representam um grande obstáculo para o seu desenvolvimento. Tal posição leva-o a defender uma teoria do conhecimento com características bastante peculiares, fundamentada em suas concepções metafísicas sobre o racionalismo e o realismo, possuindo um caráter falibilista.

Essa teoria do conhecimento afirma que é possível adquirirmos conhecimento, mas que nesse processo de apreensão do mundo pode haver erros. Não existe, nessa visão, procedimento suficientemente seguro que nos permita dizer que alcançamos uma verdade certa, segura e incontestável, mas podemos, se adotarmos certos cuidados, encontrar nossos erros e buscar uma teoria mais próxima da verdade.

A razão desempenha um papel crucial nesse cenário proposto por Popper para o processo de conhecimento. Ao contrário do que almejavam os racionalistas, ela não é capaz de, por si mesma, fundar uma base sólida para o conhecimento. Mas ela pode, porém, propor regras lógicas para o julgamento de argumentos, além de desempenhar o papel de crítica, sendo decisiva na análise e escolha de teorias científicas. Pode-se afirmar, inclusive, que razão e crítica são sinônimas dentro da filosofia de Popper, a ponto de podermos chamar uma dada teoria de racional pela sua propriedade de ser criticável, ou seja, pela sua falseabilidade.

A crítica racional e o caráter falível de teorias possibilitam, dentro de um debate, três cenários possíveis: "talvez tu tenhas razão; talvez eu tenha razão; talvez nós dois não tenhamos razão, mas nunca nós dois teremos razão, porque a minha posição é contrária à tua" (SIECZKOWSKI, 2012, p. 37). Embora não evite a possibilidade cética, já que pode ser o caso de ser impossível estabelecer o conhecimento, a crítica evita o dogmatismo, já que evita o blindamento de teorias à dúvida, uma vez que, para que exista crítica, é necessário a possibilidade do contraditório. Assim, teorias não são nunca tomadas como verdades absolutas, mas sim avaliadas segundo sua falibilidade.

Esse aspecto falibilista do conhecimento está ligado à teoria do conhecimento objetivo defendido por Popper. Existe o que chamamos de conhecimento subjetivo, que diz respeito aos estados mentais de um sujeito conhecedor em um determinado momento, e o conhecimento objetivo, que é constituído pelas teorias, argumentos e problemas acerca de uma determinada questão e que independem da crença subjetiva de alguém (POPPER, 1999, p. 110111).

A criticabilidade de uma determinada teoria independe de seu status de desenvolvimento. A objetividade do conhecimento defendida por Popper leva a um estatuto de independência das teorias em relação à subjetividade do cientista. Teorias são consideradas criações da mente humana; porém, existem problemas e possíveis consequências de tais teorias que ainda não foram, e talvez jamais sejam, 
fruto de problematização por algum ser humano e, mesmo assim, existem subjacentes à teoria.

Podemos criar teorias para resolver problemas encontrados, "Mas no momento em que produzimos essas teorias elas criam novos problemas, não pretendidos e inesperados, problemas autônomos, problemas a ser descobertos." (POPPER, 1999, p. 157).

A ideia de dar vida própria às nossas teorias é desvincular a epistemologia de seus laços subjetivos. Deste modo, poderiam desaparecer todos os homens do planeta, mas as ideias permaneceriam e poderiam ser decifradas e discutidas por outros seres inteligentes que porventura viessem parar aqui. As teorias poderiam ser refutadas e nós sobrevivermos, fazendo conjecturas cada vez mais ousadas. É neste sentido que podemos falar de "conhecimento objetivo". (SANTOS, 2012, p. 118).

A ciência, e podemos afirmar todo o conhecimento, é resultado de um processo de interação do homem com a natureza e que, na leitura de Popper, são produto da capacidade criativa do homem, e são desenvolvidas como uma habilidade de adaptação. A descoberta científica é classificada como um tipo especial de modificação de comportamento e que segue um mecanismo de adaptação, podendo "ser considerada como um instrumento usado pela espécie humana para se adaptar ao ambiente, para invadir novos nichos ambientais, e até para inventar novos nichos ambientais" (POPPER, 1978, p. 51-52). Esse processo de descoberta, segundo Popper, segue um método geral, denominado de "método das tentativas, dos erros e acertos - que é, fundamentalmente, o mesmo usado pelos organismos no seu processo de adaptação" (POPPER, 1972, p. 343).

Semelhante ao processo evolucionário biológico, assim também a ciência passaria por um processo de variação e seleção de teorias composto por fases que se iniciam pelos problemas, que suscitam a criação de teorias e a seleção através da eliminação de erros (POPPER, 1978, p. 53). Assim, o esquema geral para o desenvolvimento do conhecimento científico é descrito por Popper pelo esquema:

$$
P 1 \rightarrow T T \rightarrow E E \rightarrow P 2
$$

Esse esquema resume o método de conjecturas e refutações proposto por Popper, tomando P1 como o problema inicial; TT, teoria experimental (tentativetheory), é uma primeira solução; $E E$, eliminação de erros, é a etapa de exame crítico de TT, levando em consideração evidências disponíveis ou a comparação com outras teorias que tentem responder o mesmo problema; e P2 é a situação-problema resultante da tentativa de solucionar o problema inicial, reiniciando o ciclo de conjectura e refutação (POPPER, 1999, p. 159-160).

Popper afirma que o desenvolvimento científico percorre um percurso semelhante a esse, que por vezes conta diversas teorias que precisam ser 
comparadas e selecionadas na etapa $E E$. Assim, a etapa $E E$ se reveste de importância especial, já que essa é a etapa da crítica, onde regras racionais devem ser aplicadas para que possamos escolher a teoria que melhor resolva o problema.

Esse processo evidencia o aspecto conjectural ou hipotético do conhecimento. De acordo com esse modelo, teorias não respondem de maneira definitiva a todos os problemas, uma vez que a resposta provisória alcançada pode suscitar uma nova série de problemas que podem ou não ser respondida por essa teoria. Se os novos problemas, $P 2$, forem respondidos por essa teoria, podem surgir uma série de consequências desconhecidas a partir dessa nova teoria e que sequer havia sido colocada, mas que só foi possível diante do primeiro problema ao qual ela pretendeu responder. Esse caráter objetivo da teoria possibilita que, mesmo sem a proposição de um novo corpo teórico, seja possível a ampliação de nosso conhecimento. Porém, caso a teoria em questão seja incapaz de responder ao novo problema, novas teorias terão que ser criadas e testadas.

Esse processo contínuo de formulação de novas teorias, que se firmam provisoriamente em respostas aos problemas conhecidos até então, são frutos do intelecto humano e são passíveis de verificação na realidade, mas se contrapõe à pretensão de fundamentação da ciência de maneira certa e indubitável. Teorias são criadas para tentarem explicar a realidade, mas às vezes falham nessa tentativa, constituindo-se como conjecturas ou hipóteses.

\begin{abstract}
Muitas vezes falhamos e perecemos com as nossas conjecturas errôneas. Mas às vezes chegamos bastante perto da verdade para sobreviver com nossas conjecturas. E no nível humano, quando está à nossa disposição uma linguagem descritiva e argumentativa, podemos criticar sistematicamente nossas conjecturas. É este o método da ciência. (POPPER, 1999, p. 95).
\end{abstract}

A história do desenvolvimento do conhecimento humano não passa, assim, de uma sucessão de conjeturas lançadas que às vezes alcançam sucesso e se sustentam, às vezes falham. Popper conclui que o melhor que o homem consegue fazer em termos de conhecimento é lançar conjecturas sobre o mundo e verificar se as hipóteses levantadas se adéquam com a realidade. E, assim, o conhecimento progride de uma maneira um tanto paradoxal:

Quanto mais aprendemos sobre o mundo, quanto mais profundo nosso conhecimento, mais específico, consciente e articulado será nosso conhecimento do que ignoramos o conhecimento de nossa ignorância. Essa, de fato, é a principal fonte da nossa ignorância: o fato de que nosso conhecimento só pode ser finito, mas nossa ignorância deve necessariamente ser infinita. (POPPER, 1972, p. 57).

Esse processo gradual de construção de conhecimento pretende responder, de maneira sistemática e completa, a totalidade do mundo que conhecemos. Porém, fadados pela impossibilidade de ter acesso direto à verdade, esse processo é lento, gradual e incerto. 


\section{APONTAMENTOS FINAIS}

O projeto popperiano depende inteiramente de sua visão falibilista sobre o conhecimento. O falibilismo, embora seja uma concepção mais fraca de conhecimento em relação à concepção moderna, ainda é uma afirmação de sua possibilidade. Apresenta-se como uma solução intermediária entre o dogmatismo e o ceticismo e revela-se como uma resposta possível ante a fragilidade da capacidade humana de conhecer, sem negar o papel da razão e da experiência como fundamentais para a ciência. A ciência, nesses termos aparece como a melhor possibilidade de conhecimento para o ser humano.

Para Popper, a ideia de melhor possibilidade aparece uma vez que a ciência é capaz de assegurar a racionalidade e o progresso do conhecimento. Diferente do ideal moderno, não busca na razão a fonte segura de todo o saber, mas o melhor critério de escolha entre teorias como possíveis explicações verdadeiras do mundo através da crítica.

Porém, conjugar todos os pressupostos assumidos será um desafio para Popper. Ao abraçar o não justificionismo como forma de resposta ao problema de indução, algumas questões se colocam para o falsificacionismo. Como a proposta quer contornar o ceticismo epistemológico, faz-se necessário garantir algum processo de seleção de teorias, mesmo sem a garantia de verdade. Popper não quer cair em um falsificacionismo dogmático, mas também precisa responder ao problema Duhem-Quine. Uma das soluções tentadas e que fracassa, a ser explorada em futuramente, é o conceito de verossimilhança.

Ainda assim, a noção falibilista de Popper permanece como um importante conceito para se compreender o conhecimento humano. A ciência, embora incerta e imprecisa, se constrói pelo processo de procura pela verdade através da criatividade humana, pela proposição de teorias que buscam melhor explicar problemas não resolvidos. A busca pela verdade revela, cada vez mais, a ignorância humana: a cada passo dado, descobre-se que o tamanho daquilo que não sabemos excede, e muito, aquilo que achamos saber.

\section{REFERÊNCIAS BIBLIOGRÁFICAS}

BUENO, Otávio. Falsificacionismo, verdade e racionalidade: Popper e o programa neopopperiano. Khronos, n. 1, p. 79-116, 2010. Disponível em: <http://www.revistas.usp.br/khronos/article/view/97238/96281>. Acesso em: 18 jul. 2016.

CHIAPPIN, José Raimundo Novaes. Reconstrução racional da concepção popperiana de ciência: o racionalismo crítico como um termo médio entre o dogmatismo e o relativismo. Khronos, n. 1, p. 149-191, 2010. Disponível em: <http://www.revistas.usp.br/khronos/article/view/97241/96284>. Acesso em: 18 jul. 2016.

DESCARTES, René. Meditações. Coleção Os Pensadores. 2. ed. São Paulo: Abril Cultural, 1979. 
Reglas para ladireccióndelspíritu. Madrid: Alianza Editorial, 1996.

HUME, David. Investigação sobre o entendimento humano e sobre os princípios da moral. São Paulo: Unesp, 2004.

Tratado da natureza humana: uma tentativa de introduzir o método experimental de raciocínio nos assuntos morais. 2. ed. São Paulo: Unesp, 2009.

LAKATOS, Imre. O falseamento e a metodologia dos programas de pesquisa científica. In: LAKATOS, Inre.; MUSGRAVE, Alan. (Org.). A crítica e o desenvolvimento do conhecimento. São Paulo: Cultrix, 1979. p. 109-243.

LAM, Chi-Ming. A justification for popper's non-justificationism.Diametros: An Online Journal of Philosophy, n. 12, p. 1-24, 2007. Disponível em: $<$ http://www.diametros.iphils.uj.edu.pl/index.php/diametros/article/download/27 2/246>. Acesso em: 08 nov. 2016.

MILlER, David. Overcoming the justificationist addiction. Studia Philosophica Wratislaviensia, Instytut Filozofii Uniwersytetu Wroclawskiego, Wroclaw, Supplementary Volume, English Edition, p. 93-104, 2012.

POPPER, Karl. Conjecturas e refutações: o progresso do conhecimento científico. Brasília: Universidade de Brasília, 1972.

. Lógica das ciências sociais. Brasília: Ed. Universidade de Brasília, 1978. . O realismo e o objectivo da ciência. Lisboa: Dom Quixote, 1987. Conhecimento objetivo: uma abordagem evolucionária. Belo Horizonte: Itatiaia, 1999. A lógica da pesquisa científica. 13. ed. São Paulo: Cultrix, 2007.

SIECZKOWSKI, João Batista C. O pluralismo da tese do mundo 3 de Popper. In: OLIVEIRA, Paulo Eduardo de. (Org.). Ensaios sobre o pensamento de Karl Popper. Curitiba: Círculo de Estudos Bandeirantes, 2012. p. 32-49. Disponível em: $<$ http://www.pucpr.br/arquivosUpload/1237436911338236651.pdf>. Acesso em: 08 mar 2016.

ZAHAR, E. G. O problema da base empírica: filosofia e problemas. In: O'HEAR, Anthony. (Org.). Karl Popper: filosofia e problemas. São Paulo: Unesp, 1997. p. 57-90.

Recebido em: 17-01-2018

Aceito para publicação em: 19-11-18 